\title{
REFLEXÕES SOBRE OS EFEITOS DA TERCEIRIZAÇÃO DOS CARGOS DE APOIO NO SERVIÇO PÚBLICO FEDERAL: ESTUDO DE CASO NO INSTITUTO FEDERAL DO SUDESTE DE MG CAMPUS RIO POMBA
}

\author{
B. S. OLHER ${ }^{*}$, I. S. COSTA E M. I. TEIXEIRA \\ Instituto Federal de Educação, Ciência e Tecnologia do Sudeste de Minas Gerais - IF Sudeste MG \\ bruno.olher@ifsudestemg.edu.br*
}

Artigo submetido em janeiro/2015 e aceito em agosto/2015

DOI: $10.15628 /$ holos.2015.2692

\section{RESUMO}

A pesquisa trata da terceirização na administração pública, através da análise dos seus efeitos positivos e negativos na gestão do IF Sudeste MG - campus Rio Pomba. O estudo almejou definir as características que determinam a efetividade da terceirização ou sua ausência no Campus. Dessa forma, estabeleceu-se o contexto histórico-político no qual origina a terceirização, determinando também o que é, de fato, esse termo. Em seguida, levantou-se a principal legislação que envolve a mesma e como esta surgiu e se desenvolveu na administração pública. Para a análise do referido campus a pesquisa foi realizada com os professores, técnicos administrativos, gestores e terceirizados; com o intuito de alcançar a visão dos principais envolvidos. A pesquisa fez uso de questionário e entrevista, mediante sua análise estabeleceu a triangulação dos dados. A terceirização é uma política organizacional que exige adequação e excelente adaptação para não prejudicar o trabalho.

PALAVRAS-CHAVE: Terceirização, Administração Pública, Instituto Federal.

\section{REFLECTIONS ON THE EFFECTS OF OUTSOURCING OF SUPPORT POSITIONS IN THE FEDERAL PUBLIC SERVICE: A CASE STUDY IN INSTITUTO FEDERAL DO SUDESTE DE MG CAMPUS RIO POMBA}

\begin{abstract}
The research deals with the outsourcing in the public administration, through the analysis of its positive and negative effects in the management of IF Sudeste MG in the city Rio Pomba. The study craved define the characteristics that determine the effectiveness of outsourcing or its absence at the institute. Thus, we established the historical and political context in which originates outsourcing, determining also what is, in fact, that term. Then rose the main legislation involving the
\end{abstract}

same and how it arose and developed in public administration. For the analysis of that campus research was conducted with the teachers, administrative staff, managers and contractors; in order to achieve the vision of the principals involved. The research used questionnaires and interviews, in its analysis established the triangulation of data. Outsourcing is an organizational policy that requires adaptation and excellent adaptation to not hinder the work.

KEYWORDS: Outsourcing, Public Administration, Federal Institute. 


\section{INTRODUÇÃO}

Este artigo versa sobre um tema gerador de preocupações e dúvidas tanto para as ciências sociais quanto para as ciências jurídicas. Trata-se da terceirização, uma prática que se insere nas empresas dos mais diversos setores a fim de aumentar a produtividade, diminuir os custos, otimizar recursos, entre outros fatores.

A origem do tema terceirização data do século XVI e XVII na Europa, onde continua atuante. No Brasil o surgimento da terceirização é idealizado no contexto da crise econômica na década de 80, em que uma das alternativas foi a intervenção direta do governo na economia, com o objetivo de evitar maiores consequências, tanto para a sociedade quanto para os cofres públicos. Tal situação se instaurou por conta da crise do petróleo, iniciada na década de 70 e que se estendeu até os anos 80 . Uma das decorrências desse período de crise foi o abalo nas finanças do país, que levou à realização de diversos empréstimos. A dificuldade em saldá-los, principalmente pela pouca saída das commodities, fonte de dinheiro do país, colocou o Brasil em uma situação econômica quase incontrolável.

A solução, portanto, foi através da intervenção do estado na economia, por downsizing, que corresponde a eliminação da burocracia através da redução dos níveis hierárquicos. Enxugou-se o organograma, diminuindo o número de cargos e, consequentemente, acelerando a tomada de decisões. Estas foram medidas adotadas no cenário do governo de Fernando Henrique Cardoso (FHC), onde se instaurou o estado mínimo. Segundo Salvino e Ferreira (2009), tal conceito trata de uma ideologia que pressupõe o deslocamento das atribuições do estado perante a economia e a sociedade. No qual se legitima a não intervenção estatal, a liberdade individual e a competição entre os agentes econômicos.

$\mathrm{Na}$ administração pública a sua inserção tornou-se obrigatória através da Lei no 9.632 que dispõe sobre a extinção de alguns cargos. Esse trabalho foi motivado pelas muitas dúvidas a respeito da efetividade da terceirização, pelos impasses existentes entre os benefícios e os entraves decorrentes da sua prática. Torna-se importante essa análise por ser a terceirização presente no dia a dia de diversas organizações públicas, oferecendo a mão de obra para as atividades meio e de apoio.

Desta forma o escopo da pesquisa foi analisar o processo de terceirização no IF Sudeste MG - Campus Rio Pomba, buscando informações essenciais para identificar os efeitos da terceirização correspondentes a esta instituição. Assim foi imprescindível analisar o ponto de vista dos professores, técnicos administrativos, terceirizados e gestores. Dessa forma foi possível fazer a triangulação das informações, confrontando a visão dos atores estudados. Mediante os dados coletados se estabeleceu a análise e comparação da percepção dos interrogados, quanto à implantação do processo de terceirização e identificação dos seus efeitos positivos e negativos.

O trabalho originou-se na importância do tema para a gestão pública em que a terceirização passou a atuar de forma obrigatória conforme a Lei no 9.632. O material buscou resultados que possibilitem melhor entendimento da terceirização, não apenas para o Campus estudado, mas também como base para outras instituições. 


\section{REVISÃO BIBLIOGRÁFICA}

O arcabouço teórico teve como finalidade descrever a situação política na qual o país e a administração pública estão inseridos. Em seguida, apresentou as consequências do ingresso da terceirização mediante a extinção dos cargos que passa a atribuir a terceiros, atividades meio ou de apoio. Essas atividades são todas as que não estão diretamente ligadas à atividade fim da instituição.

Bresser Pereira (1998) classificou em quatro categorias os componentes ou processos básicos da reforma dos anos de 1990:

- A delimitação das funções do Estado, reduzindo seu tamanho principalmente em número de pessoal, através de programas de privatização, terceirização e publicização;

- A redução do grau de interferência do Estado ao efetivamente necessário através de programas de desregulação que aumentem o recurso aos mecanismos de controle via mercado, transformando o Estado em um promotor da capacidade de competição do país em nível internacional ao invés de protetor da economia nacional contra a competição internacional;

- O aumento da governança do Estado, ou seja, da sua capacidade de tornar efetivas as decisões do governo, através do ajuste fiscal, que devolve autonomia financeira ao Estado, da reforma administrativa rumo a uma administração pública gerencial em detrimento ao modelo burocrático, e a separação, dentro do Estado, ao nível das atividades exclusivas, entre formulação de políticas públicas e a sua execução; e, finalmente;

- O aumento da governabilidade, ou seja, do poder do governo, graças à existência de instituições políticas que garantam uma melhor intermediação de interesses e tornem mais legítimos e democráticos os governos, aperfeiçoando a democracia e abrindo espaço para o controle social ou democracia direta (BRESSER PEREIRA, 1998 apud REIS, 2011, p 05).

A reforma teve papel essencial para alcançar a situação desejada pelo governo de estabilização da economia. As medidas buscavam cessar o desperdício e racionalizar os gastos públicos. Com o objetivo de diminuir as despesas sem prejudicar a eficiência e qualidade dos serviços prestados.

\subsection{A terceirização}

O termo terceirização é gerador de algumas dúvidas, por falta de conhecimento de muitos sobre a sua real definição, por isso é importante defini-lo detalhada e abrangentemente. Segundo Delgado (2010), a expressão terceirização resulta de neologismo da palavra terceiro, compreendido como intermediário, interveniente.

Não se trata seguramente de terceiro, no sentido jurídico, como aquele que é estranho a certa relação jurídica entre duas ou mais partes. O neologismo foi construído pela área de administração de empresas, fora da cultura do Direito, visando a enfatizar a descentralização empresarial de atividades para outrem, um terceiro à empresa (CAFFARO, 2010).

Segundo Reis (2011), o tema terceirização não é algo desconhecido, sendo, de fato, atuante tanto no meio público quanto no privado, em todas as esferas empresariais. Uma parcela 
das empresas que utilizam a terceirização funciona sem estrutura quase nenhuma e outras tropeçam em necessidades e buscam soluções concretas para a gestão financeira.

Segundo Simões (2009), a adoção das práticas geradas pela terceirização proporciona maior satisfação para todos os envolvidos no processo. Amato (1995) descreveu que a empresa, sendo ela pública ou privada, deveria dedicar-se às atividades e às operações que realmente geram vantagens competitivas para a organização, concentrando-se em unidades de negócios que apresentam um número cada vez mais restrito de atividades. Deste modo, há diminuição do número de processos de produção, redução das estruturas administrativas e repasse de atribuições a uma rede de outras organizações, que se tornam fornecedores contratados para desempenhar as atividades não essenciais (SIMÕES, 2009).

\subsection{A terceirização na Administração Pública}

A terceirização se origina na administração pública sobre muitas controvérsias. São muitas as disparidades sobre a real efetividade do processo de terceirização e as mudanças que este sugere para a administração pública, burlando a exigência do concurso público para a inserção em uma instituição do Estado e, dessa forma, favorecendo o clientelismo político e a corrupção, como afirma Salvino e Ferreira (2009). A terceirização se insere como uma prestação de serviço, em que o vínculo com a administração pública não é feito com o trabalhador, mas sim com a empresa terceirizada, dessa forma o que se contrata é o serviço e não o trabalhador em si.

Pode-se dizer que a semente da terceirização pública iniciou através do Decreto-Lei 200/67, estabelecendo diretrizes para a Reforma Administrativa. Esse decreto é apenas o início de uma grande reforma que se estabelece na administração pública, trata-se de adequações necessárias diante da nova realidade econômica vivenciada no país, com os ideais do estado mínimo que surgem nesse período. De acordo com Salvino e Ferreira (2009), ao Estado Mínimo cabe o papel de garantir a ordem, a legalidade, e concentrar sua ação executiva naqueles serviços mínimos necessários. Essa ideologia surge como reação ao padrão de acumulação vigente.

A referida proposta visa à descentralização que tem o intuito de diminuir a máquina estatal, tirando atribuições do estado. Para alcançar o objetivo da descentralização, torna-se incontestável a inserção de uma entidade privada na administração pública, com a responsabilidade das atividades secundárias. Coube, portanto, o respaldo mais efetivo da lei, que se inicia com a Lei no 5645/70, que especifica, de forma minuciosa, as funções que poderiam ser exercidas por terceirizados na administração pública. A legalização da atividade de terceirizar é seguida por novas leis que detalham a terceirização, algumas exclusivamente sobre o tema licitação, como a Lei 8666/93. Essas leis são importantes, porém não suficientes, sendo necessários novas leis e decretos que contemplem todas as carências específicas dessa forma de trabalho e ajuste os detalhes para a maior rigidez e melhor funcionamento desse serviço na administração pública. O respaldo legal é essencial por ser uma relação de prestação de serviço muito delicada, entre a gestão pública e privada.

Inicialmente a terceirização apresenta uma grande vantagem, por ser uma opção de serviço de apoio especializado, através de empresas responsáveis e que concorrem em licitação, assim, teoricamente, selecionando a melhor empresa. Essa prestação de serviço correspondia à solução para todos os problemas organizacionais, retirando as atribuições com esses funcionários 
por parte da administração pública; dessa forma tornando uma boa opção para substituir os cargos extintos. $O$ fato da terceirização é interessante por estimular a concorrência que segundo Santos (2010) se dá por um movimento de integração constantemente realizado, dessa forma promovendo o aperfeiçoamento dessas empresas.

A decisão em terceirizar deve levar em conta uma série de fatores, trata-se de uma decisão estratégica em que devem ser analisados os aspectos de curto, médio e longo prazo. Na administração pública a licitação deve resguardar sempre a integridade da empresa a ser contratada, tanto no ato da licitação quanto no decorrer da prestação do serviço.

Quanto às desvantagens do processo de terceirização, pode-se atribuir muitos critérios, a princípio ela reduz a diferenciação da empresa contratante, abrindo espaço para que outras pessoas conheçam os seus diferenciais e, consequentemente, possam divulgá-los externamente. Outra grande desvantagem, diz respeito à eficiência, que é um dos princípios da administração pública. Este é um conceito econômico que qualifica atividades e muito se questiona a respeito, pois as atividades elaboradas pelos terceirizados nem sempre se desenvolvem de forma eficiente. Fato este de extrema importância, pois a eficiência deve ser o princípio básico da terceirização, como afirma Salvino e Ferreira (2009) sobre o significado da terceirização: "É uma forma de parceria traduzida na busca pela eficiência".

Diante da junção dessas duas realidades distintas, terceirização e administração pública, é fato que não seria uma relação de fácil adaptação. Todavia o direito e a administração pública se adaptam com frequência para o melhor funcionamento e consequente eficiência dessa prestação de serviços nos órgãos da gestão pública federal.

\section{METODOLOGIA}

Esta pesquisa é caracterizada como descritiva pelo fato de buscar descrever o processo de terceirização na instituição de ensino IF Sudeste MG. Por apresentar como objetivo a identificação e análise das visões dos terceirizados, gestores, professores e técnicos administrativos. As pesquisas descritivas são, juntamente com as exploratórias, as que habitualmente realizam os pesquisadores sociais preocupados com a atuação prática. Assim, confirma-se o caráter da pesquisa, por ser algo habitual, com atuação prática e adequada para o local estudado, no caso, o IF Sudeste MG Campus Rio Pomba.

O estudo descritivo exige que o pesquisador delimite as técnicas que serão utilizadas na pesquisa, as quais sejam ideais para a coleta e interpretação dos dados; a fim de garantir validade científica à mesma. Os dados analisados foram classificados como primários e sua coleta foi realizada mediante aplicação de questionário, elaborada com uma amostra dos colaboradores terceirizados, técnicos administrativos e professores efetivos do Campus. O trabalho também visou a opinião e experiência dos gestores, através de entrevista semi-estruturada. 0 método de pesquisa utilizado para as entrevistas com os gestores foi o não estruturado, a fim de permite liberdade ao entrevistado. Esse método garante que o entrevistado possa responder abertamente, pois o tema se desenvolve no fluir da conversa. Um ponto positivo desse método é permitir ao entrevistado a percepção das diferenças individuais e das mudanças, garantindo um maior conhecimento do tema que está em foque. 
A coleta de dados no Campus Rio Pomba ocorreu com a aplicação dos questionários estruturados mediante amostragem de servidores e terceirizados, de acordo com o setor de lotação.

Os dados coletados através dos questionários foram trabalhados através do software SPSS (Statistical Package for the Social Sciences), onde utilizou-se, para a análise, as variáveis frequência e percentual.

Com a finalidade de completar e engrandecer o conteúdo e consequentemente, os resultados da pesquisa, foram coletados informações não estruturada com os gestores e diretor do Campus Rio Pomba. A apreciação desses dados se deu através de análise de conteúdo. Segundo Bardin (1995) essa técnica de investigação tem por finalidade a descrição objetiva, sistemática e quantitativa do conteúdo manifesto da comunicação.

Os dados analisados apresentam a visão dos servidores, colaboradores terceirizados e gestores do Campus Rio Pomba a respeito do processo de terceirização no mesmo. Para melhor compreensão dos dados realizou-se a separação das análises por categoria de entrevistados, comparando-as quando necessário.

\section{ANÁLISE DOS DADOS}

\subsection{Análise dos questionários aplicada aos colaboradores terceirizados}

Os dados extraídos da pesquisa correspondem ao grupo de terceirizados, que apresentam características específicas. Assim, para melhor conhecimento desses dados, realizou-se um levantamento do perfil socioeconômico para traçar análises compatíveis com a realidade desse grupo no Campus Rio Pomba. Através dos questionários analisados, constatou-se que estes apresentam uma porcentagem de $50,6 \%$ de homens e $49,4 \%$ de mulheres, uma divisão quase perfeita dos sexos, na qual a faixa etária varia muito. A faixa etária mais presente é a de 31 a 40 anos, com 36,4\%; seguida por 41 a 50 anos com $26 \%$, até 30 anos $23,4 \%$ e de 51 a 60 anos com $11,7 \%$. Uma importante característica levantada na pesquisa está relacionada ao incentivo a estudos e capacitação, o que é extremamente necessário e não ocorreu até então, pois segundo os dados apenas $14,3 \%$ dos terceirizados estão estudando ou fazendo alguma qualificação. Esse fato é decorrência da falta de apoio à capacitação e a ausência de incentivos ao crescimento profissional.

Foram analisados dados importantes para estabelecer o perfil dos terceirizados do Campus. A princípio foi estabelecida a escolaridade desses colaboradores, devido à importância que representa na formação do indivíduo. A Figura 1 apresenta graficamente a escolaridade dos terceirizados.

Os números demonstram uma maioria com escolaridade baixa e incompleta; onde $31 \%$ não concluíram nem o ensino fundamental, seguido por $29 \%$ de terceirizados que concluíram o ensino médio; dado este mais satisfatório. Tem-se ainda $22 \%$ que concluíram o ensino fundamental e apenas $4 \%$ com ensino superior completo. 


\section{Escolaridade}

\begin{tabular}{|c|c|}
\hline Ensino Médio Incompleto & Ensino Médio Completo \\
\hline Ensino Superior Incompleto & Ensino Superior Completo \\
\hline Pós Graduação & \\
\hline
\end{tabular}

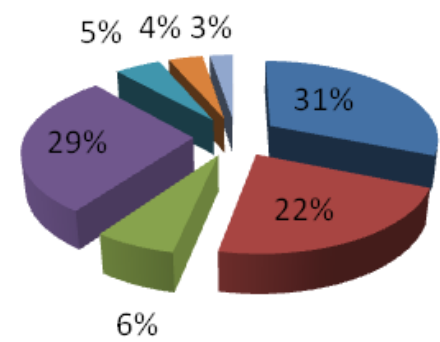

Figura 1: Escolaridade dos terceirizados Fonte: Dados da pesquisa

Outro tema necessário e polêmico diz respeito ao salário, que é uma preocupação presente desde o início da terceirização. Mesmo sendo um trabalho de apoio e suporte, é de extrema importância que esses profissionais sejam bem remunerados e adquiram o reconhecimento do seu trabalho, o que será refletido no seu desempenho profissional. A motivação é o fator-chave para o alcance dos objetivos propostos pelo ambiente de trabalho.

\section{Renda Familiar}

$\begin{array}{ll}\text { - } 1 \text { Salário } & \text { até } 2 \text { salários } \\ \text { de } 5 \text { a } 10 \text { salários } 2 \text { a } 5 \text { salários }\end{array}$

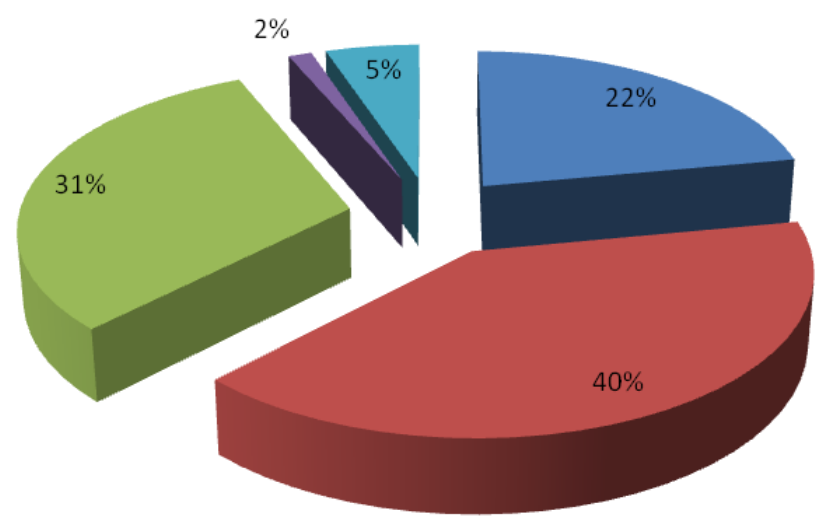

Figura 3: Renda familiar dos terceirizados

Fonte: Dados da pesquisa

Buscou-se compreender qual a participação do salário dos terceirizados em suas casas, qual a importância que essa renda representa para as famílias. Para tanto foi analisada a renda das famílias dos terceirizados, dados demonstrados na figura 2, nota-se que a maioria apresenta uma renda familiar acima de 1 salário, nesse momento é importante ressaltar que em 22\% dessas residências a renda é exclusiva do trabalhador terceirizado, para os $73 \%$ restante, há outros trabalhadores na residência. Para $22 \%$ das famílias a única renda corresponde ao trabalho 
no Campus, reforçando a necessidade de uma efetiva gestão de pessoas, com respeito ao trabalhador e responsabilidade com os seus direitos.

Muitos afirmam que o trabalho no Campus é o seu primeiro com carteira assinada, uma importante informação que realça o valor desse trabalho para os profissionais.

Outro aspecto importante refere-se à satisfação dos terceirizados em fazer parte da instituição, sendo esse um fator motivacional excelente e sem custos para a administração pública. O fato de vestirem a camisa e se considerarem realmente funcionários da instituição motiva-os e garante grandes vantagens para o Campus. Esses dados foram coletados paralelamente à aplicação dos questionários através de conversas informais, o que é um reflexo da postura e intenção do Campus. Apesar da auto motivação em trabalhar no Campus, os terceirizados exibem muitos aspectos que podem ser melhorados. Abaixo segue uma tabela com os desejos de melhorias por parte dos terceirizados.

Tabela 1. Aspectos para melhorar o trabalho dos terceirizados

\begin{tabular}{lcccc}
\hline & Frequência & Porcentual & \% válida & \% acumulativa \\
\hline Melhores salários & 24 & 31,2 & 34,3 & 34,3 \\
Trabalho em equipe & & 1,3 & 1,4 & 35,7 \\
Nada & 16 & 20,8 & 22,9 & 58,6 \\
Vale Transporte & 1 & 1,3 & 1,4 & 60,0 \\
Convivência & 3 & 3,9 & 4,3 & 64,3 \\
Aumentar o número de funcionários & 6 & 7,8 & 8,6 & 72,9 \\
Outros & 27 & 35 & 8,6 & 81,4 \\
Total & 77 & 100,0 & & \\
\hline
\end{tabular}

Fonte: Dados da pesquisa

Igualmente a muitos outros empregos e cargos, o desejo predominante é o de melhoria salarial. Pode-se justificar essa escolha por ser a que altera de forma mais eficaz na melhoria de vida desses colaboradores, pois, certamente, esse aspecto isolado não garante a satisfação desses, muito menos a sua permanência na organização.

O maior problema a ser levantado não é exatamente quais são esses aspectos que desfavorecem o trabalho dos terceirizados, mas sim quais as decisões que a empresa tomará ao estar munida desse resultado. Pois, percebe-se que não há interesse de conhecimento, muito menos de mudança por parte desta que de fato, é a responsável por esse papel. Devido ao fato de haver um abandono, no que se refere ao aspecto pessoal por parte da empresa contratada para com os seus colaboradores. O tratamento é muito superficial causando um distanciamento e em alguns casos a falta de identidade, levando alguns terceirizados a acreditarem que são funcionários do Campus e a desconhecerem até mesmo o nome da empresa que o contratou.

\subsection{Análise dos questionários aplicado aos servidores}

Os servidores - técnicos administrativos e professores- apresentam um papel ímpar para a referida pesquisa, por atuarem no mesmo ambiente de trabalho dos terceirizados e por isso serem capazes de qualificar e analisar sobre um olhar mais rigoroso, o processo de terceirização no Campus.

Determinados servidores contribuíram ainda mais com a pesquisa por terem vivenciado o processo de mudança, de servidores para terceirizados, no Campus. Pois anteriormente à lei os 
cargos que hoje são ocupados por terceirizados antes eram de funcionários públicos. Portanto a contribuição destes acrescentou informações importantes, a respeito de um grande impasse dessa mudança, a distribuição dos funcionários públicos que atuavam nos cargos, agora, excluídos da mesma administração. Inegavelmente houve o amparo a estes servidores, mesmo não podendo exercer o mesmo cargo, estes devem permanecer na instituição. Porém a alocação desses profissionais não foi considerada justa por todos.

A primeira análise com esse grupo buscou extrair a percepção que os técnicos administrativos e professores têm a respeito da terceirização no Campus. Em posse da tabela 2 é possível afirmar que os servidores reconhecem a atuação de dois regimes de trabalho dentro do Campus, efetivos e terceirizados. Muitos completam a resposta realçando o bom trabalho prestado pela classe. Todos entendem a importância do serviço prestado por estes profissionais, sendo um apoio para que as principais atividades da instituição se desenvolvam da melhor forma.

Tabela 2. Conhecimentos dos professores e TAE sobre a terceirização

\begin{tabular}{l|l|c|c|c}
\hline \multicolumn{2}{l|}{} & TAE & Professor & Total \\
\hline & Nada & $1,8 \%$ & $6,9 \%$ & $4,4 \%$ \\
\cline { 2 - 5 } & Muito pouco & $5,4 \%$ & $10,3 \%$ & $7,9 \%$ \\
\cline { 2 - 5 } $\begin{array}{l}\text { O que você conhece sobre o } \\
\text { processo de terceirização } \\
\text { neste Campus? }\end{array}$ & $\begin{array}{l}\text { Sei que tem alguns } \\
\text { servidores terceirizados } \\
\text { trabalhando nesta } \\
\text { instituição }\end{array}$ & $64,3 \%$ & $60,3 \%$ & $62,3 \%$ \\
\cline { 2 - 6 } & $\begin{array}{l}\text { Conheço os setores e } \\
\text { cargos terceirizados }\end{array}$ & $28,6 \%$ & $22,4 \%$ & $25,4 \%$ \\
\hline Total & $100,0 \%$ & $100,0 \%$ & $100,0 \%$ \\
\hline
\end{tabular}

Através de todos os dados coletados pôde-se atribuir duas faces ao processo de terceirização no Campus, com seus benefícios e entraves. Em seguida realizou-se o levantado e análise de alguns problemas decorrentes da terceirização de cargos extintos no Campus Rio Pomba. Dentre esses problemas evidenciam-se características correspondentes a todas as partes envolvidas; aos terceirizados, à empresa contratada e à gestão federal, através da Lei que insere a terceirização e as demais que a regulam. Estes aspectos envolvem administração, adequação a

Há a ausência de amparo legal à terceirização na administração pública, a maior rigidez da lei, acarretará, já no ato da licitação, em garantias dos direitos dos colaboradores terceirizados, os deveres da empresa e consequentemente maior qualidade do serviço prestado para o contratante, no caso o IF Sudeste MG campus Rio Pomba. Dessa forma, outros aspectos negativos serão sanados, como a precarização do trabalho, a falta de compromisso da empresa e a falta de gerência nos serviços. Certamente, essas alterações já acarretarão em grandes benefícios. Assim a terceirização deixa de ser apenas um escape e passa a ser uma estratégia de gestão de pessoas.

Existe também o aumento dos gastos como um aspecto levantado pelos servidores. Como já foi argumentado por um gestor, a terceirização gera um gasto muito alto para a administração pública, mesmo que o servidor terceirizado só tenha acesso a metade desse valor. Abaixo segue a figura 3 com a visão dos servidores quanto ao número de terceirizados. 
Outra análise importante diz respeito a uma necessidade aparente, relativa ao número de colaboradores terceirizados para cada função. A maioria dos servidores considera que o número de terceirizados não é suficiente para a quantidade de trabalho, ou seja, a mão de obra não é suficiente para o trabalho demandado. Através da pesquisa é possível constatar que o número de terceirizados não está adequado; as opiniões se dividem considerando a quantidade insuficiente ou razoável. E uma minoria acredita estar equilibrado. Informações estas confirmadas através do gráfico a seguir. Através das respostas dos servidores, a primeira alteração para com os terceirizados está na implantação de novas políticas, sendo estas apenas organizacionais ou legais.

\section{Visão dos servidores quanto ao número de terceirizados

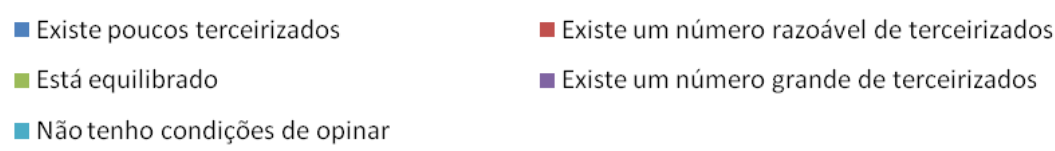

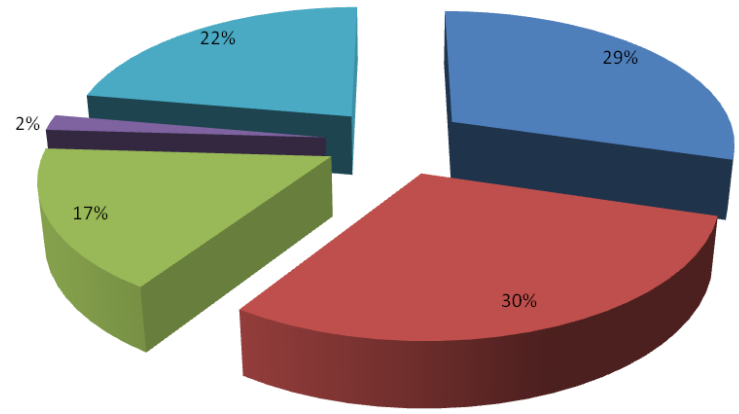

Figura 3: Visão dos servidores quanto ao número de terceirizados Fonte: Dados extraídos da pesquisa

Qualquer mudança realizada em um ambiente de trabalho deve ser acompanhada desde sua origem, analisando cuidadosamente as alterações por ela geradas. A princípio deve ser realizada uma reunião para a apresentação da proposta, informando a todos os envolvidos qual é a nova política a ser utilizada no ambiente de trabalho; quais os motivos de sua implantação e os benefícios que serão por ela gerados. Essas são políticas organizacionais de grande valia para a melhor inserção e adaptação dessa estratégia de trabalho que é a terceirização

Em geral, os servidores apresentam diversos questionamentos quanto à eficiência do processo de terceirização. Concluindo que diante da situação atual de permanência da terceirização são cabíveis diversas mudanças; para que de fato terceirizar não prejudique a gestão pública, mas venham contribuir com a mesma.

\subsection{Análise da entrevista realizada com os gestores}

A princípio a terceirização foi um processo que gerou grande dificuldade de adaptação, pela rigidez da Lei e o alto grau de burocracia para a contratação da empresa terceirizada. Os gestores relatam que o início do processo no IF apresentou grandes dificuldades e afirmam a necessidade de capacitação dos servidores do Campus para desempenharem essa nova função.

Com a necessidade de inserir a terceirização tem-se um essencial aspecto a cargo da contratante, que no caso é o IF Sudeste de MG, esse diz respeito à reputação da empresa 
contratada. Fator essencial para o bom desenvolvimento da atividade terceirizada, sendo imprescindível que se conheça os trabalhos já realizados pela empresa e qual a imagem que esta tem apresentado ao mercado.

Outra dificuldade analisada foi a de alocação desses colaboradores, antes em cargos efetivos e que agora apresentam um cargo banido da administração pública. Como foi levando pelos técnicos e professores, esse foi um aspecto negativo enfatizado durante a aplicação dos questionários: muitos servidores relatavam que em alguns casos não era devida a alocação dos servidores que tiveram seus cargos banidos, principalmente no que diz respeito à qualificação destes para o cargo.

Há também uma divergência de valores entre o que é pago para a empresa terceirizada e o que de fato chega ao funcionário, que é o principal responsável pelo serviço que a empresa presta à instituição. $O$ valor que é pago por funcionário nos contratos está longe do salário que os terceirizados realmente recebem. $O$ que se constata através desse relato de um dos gestores: "No modelo de terceirização existente, a única vantagem para a empresa é em razão de a administração pagar à empresa terceirizada, por exemplo, mil reais para cada funcionário e nas mãos dos funcionários só chegavam quinhentos reais" (N.G.P). Esse é um aspecto preocupante e alvo de análise por parte da instituição, pois o instituto entende e deseja que os terceirizados devam ser bem remunerados. Esse valor alto muitas vezes é justificado pelo excesso de encargos a serem pagos às empresas.

Nesse ponto há mais um importante aspecto que deve ser considerado. Trata-se da divergência de salários entre funcionário público e servidor terceirizado. "Uma grande desvantagem no tratamento legal diferenciado é a questão da remuneração, onde você tem servidores terceirizados com a mesma função do efetivo, em que o salário do último chega a três vezes ou mais a do terceirizado, fora os benefícios de auxílio alimentação, plano de saúde. Tendo esses dois servidores em um mesmo ambiente de trabalho e exercendo a mesma função e com tratamentos legais diferentes, não é fácil de harmoniza esse convívio" (A.P.N.J.). Sabe-se que os cargos não são os mesmos para terceirizados e efetivos, mas em determinadas situações ocorre esse impasse onde terceirizados e efetivos desempenham as mesmas funções ou funções similares. Porém os salários não coincidem, pelo contrário, apresentam uma grande diferença.

Durante a entrevista, o gestor levantou uma importante mudança que pode acarretar em diversas vantagens para a instituição, que é a mudança de o fiscal dos terceirizados ser um funcionário efetivo do Campus. "(...) mas a vigilância a essas empresas tem que ser efetiva e muitas vezes tem que haver cursos para a capacitação desses fiscais que necessariamente precisa ser um funcionário efetivo" (N.G.P). A finalidade de tal procedimento é gerar uma distribuição adequada das funções de cada colaborador terceirizado e um correto acompanhamento do serviço prestado, com o objetivo de garantir uma ideal fiscalização e uma cobrança mais efetiva desses colaboradores. Esse fiscal deve ter ciência de suas atribuições e conhecer detalhadamente a empresa e as obrigações que esta estabeleceu em contrato com a instituição, atuando desde o momento da licitação. Essa solução será importante, também, para evitar a maior desvantagem apontada nessa pesquisa, que é a rotatividade. Diante da atenção e do rigor de um funcionário efetivo do Campus e preparado para atuar como fiscal da empresa terceirizada, dificilmente haverá a necessidade de despedir ou trocar algum colaborador terceirizado, na medida em que estes apenas serão contratados se estiverem capacitados para desempenharem o cargo, e receberem o treinamento e informações necessárias. Porém, legalmente, essa alteração não é 
possível, pois, atualmente, a interação entre o Instituto e a empresa terceirizada é restrita ao preposto, que é um funcionário da própria empresa terceirizada.

Há uma grande diferença dos efetivos para os terceirizados, que pode ser visualizada na ausência de plano de carreira e capacitação para os terceirizados. Apesar de a capacitação ser um aspecto já levantado no período da licitação, em muitos casos ele não ocorre, ou ocorre de forma ineficiente. Esse cenário se configura como um aspecto negativo, visto que exime esses colaboradores de crescerem em suas carreiras, buscando crescimento profissional, treinamento e a obtenção de um mínimo de estabilidade em seu trabalho. Não há uma motivação ao crescimento no cargo ou o apoio à profissionalização com o objetivo de capacitar o colaborador, assim gerando uma estagnação desses colaboradores, que não visualizam melhores oportunidades dentro da organização.

Muitos outros aspectos negativos foram levantados pelos funcionários efetivos do Campus. Através da visão desses trabalhadores que apresentam uma estrutura de trabalho bem mais eficiente e vantajosa, é possível observar que se faz necessário uma atenção maior a essa política trabalhista, visando a melhoria na qualidade do trabalho e consequentemente dos seus efeitos.

Torna-se importante ressaltar alguns aspectos positivos decorrentes dessa política. Apesar das muitas desvantagens da terceirização cabe analisar o outro lado, os aspectos que ainda a tornam uma opção para substituição aos cargos extintos da administração pública.

Conforme o objetivo da lei, a terceirização alcança no IF Campus Rio Pomba uma diminuição das obrigações do Estado, ao diminuir significativamente a carga de funcionários na responsabilidade da administração pública, gerando diminuição das funções com gestão de pessoas. Através da terceirização, as obrigações com os funcionários passam a ser da empresa terceirizada que foi contratada mediante licitação. Assim transfere-se uma alta carga de atribuições, que anteriormente eram de responsabilidade da gestão pública, para uma empresa fora da instituição.

Segundo dados coletados através dos questionários aplicados e trabalhados no software SPSS o trabalho como terceirizado representa para $64 \%$ dos funcionários a principal renda da sua casa, um aspecto muito importante e que deve ser considerado, pois se refere a famílias que são beneficiadas e que dependem desse trabalho. Quando é conhecido que $31 \%$ desses trabalhadores têm apenas o ensino fundamental incompleto, reforça ainda mais a necessidade que estes têm de manterem o seu emprego. Pois com a baixa escolaridade se torna difícil o emprego com carteira assinada.

Um aspecto importantíssimo que trata do desempenho no trabalho; é um dos pontos positivos que são ressaltados na pesquisa. Em geral os funcionários terceirizados desempenham bem suas funções e trabalham até mesmo com mais dedicação do que os servidores, que antes da extinção dos cargos, assumiam essas funções. "A maior vantagem seria a eficiência, pois com a terceirização alguns serviços se fossem prestados por efetivos haveria maior dificuldade na fiscalização e vigilância, mas com os terceirizados a cobrança é mais simples por que é em cima da empresa terceirizada" (N.G.P). Assim torna-se mais prática e eficiente as atividades desempenhadas por esses colaboradores, poupando a gestão pública de tais atribuições. Tal situação pode ser comprovada pelas respostas dos servidores efetivos, onde a maioria, cerca de $23 \%$ responderam que a vantagem da terceirização está na qualidade do serviço prestado, 
ressaltando o compromisso e dedicação desses colaboradores. Mesmo diante de muitas respostas diferentes, nota-se que a maioria delas se enquadra no perfil do bom desempenho dos terceirizados em suas atividades.

A fim de confirmar a preocupação existente quanto ao número de terceirizados no Campus, um dos gestores ao ser questionado se o número de terceirizados está adequado, afirma que: "Não, de forma alguma. Tem se visto nos últimos anos um aumento da matriz orçamentária aqui do Campus, mas os gastos têm aumentado em uma velocidade maior. Se aumentou o número de laboratórios, prédios e de setores, isto tudo aumenta muito a demanda de servidores, seja de auxiliares de limpeza, de auxiliar de agropecuária, de vigilância, de motorista, de diversos cargos e não tem conseguido com o orçamento aumentar o número de servidores terceirizados na proporção que deveria em razão do orçamento "(A.P.N.J.).

Outro aspecto importante e determinante se refere à adequada escolha dos funcionários terceirizados no que diz respeito à sua forma de ingresso na empresa. Sabe-se que todas as obrigações com os terceirizados são de inteira responsabilidade da empresa terceirizada, como afirma um dos gestores do Campus "A gestão de pessoas no caso dos terceirizados é feita pela empresa" (N.G.P.). Para analisar esse quesito os terceirizados foram questionados sobre o método de seleção utilizado na contratação deles, e diante da pesquisa realizada conclui-se que a maioria, 34\% respondeu que foi por meio de indicação de parentes ou amigos, 31\% através de análise de currículo e apenas $11 \%$ através de entrevista. Esse resultado pode ser justificado diante da característica da empresa, por: até então, não ser uma empresa de origem local, eles optam pela indicação por ser uma opção mais rápida e em geral satisfatória. O recrutamento e seleção de pessoal dessas empresas são, portanto superficiais, por não passar por uma seleção criteriosa e não exigir uma análise meritocrática do cargo. O que pode gerar uma seleção de pessoal injusta, limitando os concorrentes.

Mantendo o contexto da gestão de pessoas, algo essencial para uma boa administração é a satisfação dos colaboradores, mas como satisfazê-los se não se conhece a opinião e necessidades dessas pessoas? No caso da terceirização em muitos momentos os funcionários se sentem desamparados, mesmo que estes atuem em climas agradáveis. A empresa se posiciona de forma a se distanciar do colaborador, estando na maioria das vezes ausente e quando se aproxima é de forma pouco calorosa, evitando a ocorrência de um novo contato. Em alguns casos os terceirizados nem conhecem a empresa para a qual trabalham, não sabem a sua origem, quem são os donos, o máximo que sabem é o nome da empresa. Dessa forma desestimulando ainda mais os colaboradores que não têm como se identificarem com a empresa e se sentirem valorizados por fazerem parte dela.

Muitos terceirizados tiveram receio em responder à questão que será analisada abaixo, mesmo com a garantia de não haver a divulgação do nome ou qualquer risco ao seu trabalho. Quanto ao Campus não há muito a ser feito, pois se trata de responsabilidades que não lhe competem, mas sim, são de responsabilidade da empresa contratada. Mas sabe-se que o ambiente de trabalho é proporcionado pelo Campus, sendo importante que este possibilite ao terceirizado um ambiente favorável para a atuação do seu trabalho. Certamente esta é uma preocupação já existente; como relatado por um dos gestores “(...) vem se praticando essa integração (com os terceirizados) no dia-a-dia, com a valorização dos servidores terceirizados, não aceitando de forma alguma nenhum desrespeito a esses servidores por parte de efetivos ou por parte de alunos. Tem se também neste processo de integração, chamado os servidores 
terceirizados para confraternizações aqui no Campus (A.P.N.J.)." Assim, fica evidenciada uma preocupação da gestão em garantir um ambiente adequado para atuação desses colaboradores.

Diante das respostas oferecidas pelo terceirizados quanto aos aspectos de melhoria no trabalho, compreende-se que apenas uma delas, que é a convivência, diz respeito à interação entre os colaboradores. Esse é um aspecto que o Campus pode melhorar, mas em presença das respostas anteriores comprovando a boa interação tanto entre os alunos, quanto entre os efetivos, entende-se que essa resposta pode estar relacionada à convivência entre os terceirizados deixando, então, de ser uma responsabilidade do Campus.

A terceirização apresenta algumas características comuns nas organizações onde são implantadas. Dentre as características comuns à terceirização, algumas se fazem presentes no Campus Rio Pomba, como a melhor qualidade no serviço, redução do quadro direto dos empregados, desmobilização para greves, eliminação de ações sindicais e trabalhistas.

Diante do amparo legal, será possível, já no ato da licitação, garantir os direitos dos colaboradores terceirizados, os deveres da empresa e consequentemente maior qualidade do serviço prestado para o contratante, no caso o IF Sudeste MG campus Rio Pomba. Dessa forma, outros aspectos negativos serão sanados, como a precarização do trabalho, a ausência de compromisso da empresa e a falta de gerência nos serviços. Certamente, essas alterações já acarretarão em grandes benefícios. Assim a terceirização deixa de ser apenas um escape e passa a ser uma estratégia de gestão de pessoas.

\section{CONSIDERAÇÕES FINAIS}

O referido trabalho possibilitou identificar relevantes mudanças decorrentes da extinção dos cargos públicos. Algumas podem ser caracterizadas como positivas e outras como negativas para a administração pública. O propósito do trabalho se encontra na identificação dessas alterações e a consequente elaboração das mudanças necessárias.

A terceirização alcança seu objetivo inicial, de eliminar atribuições da gestão pública através da contratação de uma empresa terceirizada, porém essa mudança não se realiza de forma estratégica, mas apenas como uma alternativa para suprir os cargos extintos dessa gestão. Ao referido trabalho, portanto, coube o dever de analisar até que ponto essa mudança foi benéfica.

No Campus Rio Pomba a terceirização apresentou, desde o seu início, dificuldades de implantação, além de requerer atenção cada vez mais constante no que diz respeito ao seu processo de adaptação, diante das novas leis que surgiam e ainda surgem, para melhor adequar essa política ao perfil da administração pública brasileira.

Quanto às políticas legais, elas são de fato leis e decretos que tornem a terceirização mais fácil e correta, sendo aplicada de forma a beneficiar todas as partes; contratante, contratada e funcionários terceirizados. No período da reforma foram criadas as condições legais e objetivas para a implantação do processo de terceirização. No IF Sudeste MG Campus Rio Pomba, nota-se a necessidade de elaboração de leis mais rígidas pelo legislativo, a fim de amparar todas as partes envolvidas, com o intuito de garantir um serviço de qualidade, prestado por colaboradores motivados e a um preço justo. 
Em seguida, é importante ressaltar a necessidade do fiscal da empresa terceirizada ser um membro efetivo do Campus, como levantado pelo gestor N.G.P, para fiscalizar se todos os acordos estabelecidos no ato da licitação estão de fato se cumprindo e garantir autoridade da Instituição a atuar em prol dos terceirizados.

A pesquisa possibilitou identificar muitos entraves como rotatividade, instabilidade e baixos salários que, certamente, prejudicam e desvalorizam o trabalho dos terceirizados. Dessa forma afetam diretamente na qualidade do serviço prestado. Nota-se que há empenho por parte dos colaboradores e diante das respostas dos gestores confirmando que estes prestam um serviço de qualidade e na maioria das vezes, se esforçam para trabalharem mesmo em condições adversas. Mas para que seja uma dedicação contínua e capaz de enriquecer o ambiente de trabalho, é essencial que esses colaboradores sejam notados e tenham a atenção da empresa a qual são funcionários.

Uma solução para esses problemas pode estar no ato da licitação. Como tratado acima, se o cenário legal da terceirização se modificar, tornará essa política administrativa mais correta e eficaz. Como um primeiro passo para essas mudanças tem-se um projeto de lei de 2004 que versa sobre essa relação de trabalho, garantindo melhor amparo aos colaboradores e maiores obrigações às organizações terceirizadas. São pequenas mudanças que acarretaram no desempenho de uma gestão de pessoas adequada e de qualidade, com incentivos aos colaboradores.

Essas mudanças possibilitam novos horizontes ao IF, visto que, diante de um serviço de excelência por parte dos terceirizados, os efetivos também se sentirão motivados por terem um ambiente ainda mais favorável de trabalho. Assim será um benefício com múltiplas vantagens e que certamente aumentará a produtividade e irá melhorar a interação e visão de todos a respeito dessa política de trabalho que é a terceirização.

A partir dessa, torna-se viável novas pesquisas que possibilitem importantes conclusões em todas as formas de trabalho existentes no referido Campus e até mesmo em outras organizações que fazem uso da terceirização.

\section{REFERÊNCIAS:}

1. AMATO NETO, J. Reestruturação Industrial, Terceirização e Redes de Subcontratação. RAERevista de Administração de Empresas, v. 35, n. 2, mar-abr, p.33-42, 1995

2. BARDIN, Laurence. Análise de conteúdo. Tradução Luiz Antero Reto e Augusto Pinheiro Lisboa: Edições 70, 1995

3. BRASIL. Decreto Lei no 200, de fevereiro de 1967. Dispõe sobre a organização da Administração Federal, estabelece diretrizes para a Reforma Administrativa e dá outras providências. Diário Oficial [da] República Federativa do Brasil. Disponível em: <http://www.planalto. gov.br/ccivil_03/decreto-lei/del0200.htm> Acesso em mar. 2013.

4. BRASIL. Lei $\mathrm{n}$ - 7.596, de 10 de Abril de 1987. Altera dispositivos do Decreto-lei $\mathrm{n} 0200$, de 25 de fevereiro de 1967, modificado pelo Decreto-lei no 900, de 29 de setembro de 1969, e pelo Decreto-lei no 2.299, de 21 de novembro de 1986, e dá outras providências. Diário Oficial [da] República Federativa do Brasil. Disponível em: < http://www.planalto.gov.br/ccivil_03 /leis/l7596.htm> Acesso em Out. 2013. 
5. BRASIL. Lei $\mathrm{n} 0$ 8112, de 11 de dezembro de 1990. Dispõe sobre o regime jurídico dos servidores públicos civis da União, das autarquias e das fundações públicas federais. Diário Oficial [da] República Federativa do Brasil. Disponível em: < http://www.planalto.gov.br/cci vil_03/leis/l8112 cons.htm> Acesso em mar. 2013.

6. BRASIL. Lei no 8.666, de 21 de junho de 1993. Regulamenta o art. 37, inciso XXI, da Constituição Federal, institui normas para licitações e contratos da Administração Pública e dá outras providências. Diário Oficial [da] República Federativa do Brasil. Disponível em: < http://www. planalto.gov.br/ccivil_03/leis//8666cons.htm> Acesso em mar. 2013.

7. BRASIL. Lei no 9632, de 07 de maio de 1998. Dispõe sobre a extinção de cargos no âmbito da Administração Pública Federal direta, autárquica e fundacional, e dá outras providências. Diário Oficial [da] República Federativa do Brasil. Disponível em: < http://www.planalto.gov .br/ccivil_03/Leis/L9632.htm> Acesso em mar. 2013.

8. BRASIL. (2004), Projeto de Lei no 4330, de 2004. Dispõe sobre o contrato de prestação de serviço a terceiros e as relações de trabalho dele decorrentes. Diário Oficial [da] República Federativa do Brasil. Disponível em: < http://www.planalto.gov.br/ccivil_03/Leis/L9632.htm > Acesso em mar. 2013.

9. BRESSER-PEREIRA, Luiz Carlos. Gestão do setor público: estratégia e estrutura para um novo Estado. In: SPINK, Peter. Reforma do Estado e administração pública gerencial. Rio de Janeiro: Editora Fundação Getúlio Vargas, 1998.

10. CAFFARO, Leonardo de Mello. O pós-positivismo, o direito do trabalho e a noção de interesse público: a terceirização na administração pública e a Súmula n. 331 do TST em questão. Revista LTr: Legislação do Trabalho, Ano 74, número 12, São Paulo: LTr, 2010.

11. CPDOC/FGV. Centro de pesquisa e Documentação de História Contemporânea do Brasil. A era Vargas dos anos 20 a 1945. Disponível em:< http://cpdoc.fgv.br/producao/dossies/AEra Vargas1/anos3745/PoliticaAdministracao/DASP> Acesso em abr. 2013.

12. DIEESE. Processo de terceirização e seus efeitos sobre os trabalhadores no Brasil. Disponível em:<http://portal.mte.gov.br/data/files/FF8080812BA5F4B7012BAAF91A9E060F/ Prod03_2007.pdf> Acesso em abr. 2013.

13. MATIAS-PEREIRA, José. Curso de Administração Pública - São Paulo: Atlas, 2008.

14. REIS, Fátima dos. A reforma do Estado brasileiro no período de 1995 a 2002: reconfiguração da administração e dos serviços públicos e seus reflexos na Universidade Federal de GoiásUFG. Dissertação de Mestrado. Pontifícia Universidade Católica de Goiás, Goiânia, 2011.

15. SALVINO, Marcos Ribeiro; FERREIRA, Simone Rodrigues. A terceirização de Serviços na Administração Pública e Responsabilidade Trabalhista. Revista Novatio luris, v. 2, n. 3, p. 119-145, Jul. 2009.

16. SIMÕES, Carlos Lúcio. Terceirização no Setor Público Vantagens e Desvantagens. Nova Venécia, 2009. Disponível em:< http://univen.no-ip.biz/listamono/monografias/Administra\% C3\%A7\%C3\%A30\%20e\%20An\%C3\%A1lise\%20de\%20Sistemas/2009/TERCEIRIZA\%C3\%87\%C3 \%830\%20NO\%20SETOR\%20P\%C3\%9ABLICO-VANTAGENS\%20E\%20DESVANTAGENS.pdf> Acesso em Maio 2013.

17. VergarA, Silvia Constant. Projetos e Relatórios de Pesquisa em Administração/ Sylvia Constant Vergara.-12.ed. São Paulo: Atlas, 2010. 